\title{
RIGHT ILIAC FOSSA MASS- EVALUATION AND MANAGEMENT
}

\author{
Sunilkumar Singh Salam¹, Laitonjam Chinglensana2, Sandesh ${ }^{3}$, Nongmaithem Mackson Singh4, Manoharmayum Birkumar Sharma ${ }^{5}$
}

${ }_{1}^{1}$ Assistant Professor, Department of General Surgery, Regional Institute of Medical Sciences, Imphal, Manipur, India. ${ }^{2}$ Assistant Professor, Department of General Surgery, Regional Institute of Medical Sciences, Imphal, Manipur, India.

${ }^{3}$ Resident, Department of General Surgery, Regional Institute of Medical Sciences, Imphal, Manipur, India.

${ }^{4}$ Senior Resident, Department of General Surgery, Regional Institute of Medical Sciences, Imphal, Manipur, India.

${ }^{5}$ Professor, Department of General Surgery, Regional Institute of Medical Sciences, Imphal, Manipur, India.

ABSTRACT
BACKGROUND
Mass in the Right Iliac Fossa (RIF) has since long exercised the minds of many surgeons. The various pathologies, multiple and
varied modes of presentation of each disease entity, the difficulties encountered in investigative modality, diagnosis and treatment,
make masses presenting in RIF a difficult entity to treat even at tertiary care centres.
Aim: The study was undertaken to assess the pattern of presentation of mass in RIF and to identify factors which will help in
diagnosis and better management.

\section{MATERIALS AND METHODS}

This is a prospective observational study conducted in the Department of Surgery, Regional Institute of Medical Sciences, Imphal, Manipur, in patients with mass in RIF admitted from September 2014 to August 2016. Variables studied include age, sex, symptoms such as fever, vomiting, loss of weight, mass per abdomen, duration of symptoms, clinical signs, haematology, ultrasonography and barium study findings, mode of management, complication and outcome. Data was analysed using SPSS version 21.

\section{RESULTS}

In this study of 100 cases, $64 \%$ of cases were related to appendicular pathology either as appendicular mass or appendicular abscess. There were 14 cases of ileocaecal tuberculosis and 12 cases of carcinoma caecum. The youngest patient was 11 years old presenting with appendicular mass and the oldest was 60 years of age with carcinoma of caecum. Appendicular mass manifested most commonly between 20 - 29 years (21\%) followed by 30 - 39 years. Appendicular abscess was common in the 30 - 39 years' age group. Ileocaecal tuberculosis was common in 30 - 49 years (71.4\%). Carcinoma caecum was seen in older age group of 50 - 59 years (75\%). Appendicular mass (70.33\%) and appendicular abscess (68.75\%) were commoner in males. $71.42 \%$ of males were diagnosed with ileocaecal tuberculosis and carcinoma caecum was found in $83.33 \%$ of the male patients.

\section{CONCLUSION}

Of the 100 cases, 17 cases were managed conservatively, and 83 cases underwent surgery. Out of 40 cases of appendicular mass, 16 cases were taken up for surgery immediately, whereas rest of the 24 cases were managed by Ochsner-Sherren regimen and appendicectomy was done at a later date.

\section{KEY WORDS}

Appendicular Mass, Ileocaecal Tuberculosis, Carcinoma Caecum, Psoas Abscess.

HOW TO CITE THIS ARTICLE: Salam SS, Chinglensana L, Sandesh O, et al. Right iliac fossa mass- evaluation and management. J. Evolution Med. Dent. Sci. 2018;7(33):3642-3647, DOI: 10.14260/jemds/2018/818

\section{BACKGROUND}

Mass in the abdomen, especially mass in the RIF confronts the surgeon, paediatrician, obstetrician and gynaecologist. Thorough understanding of the anatomy and pathological processes that may occur within the abdomen are essential for an accurate diagnosis and plan of treatment. Some patients will require immediate surgical intervention, whereas others will improve with non-operative treatment. As far as masses are concerned, abdomen is indeed a "Temple of Surprises."

'Financial or Other Competing Interest': None.

Submission 02-07-2018, Peer Review 27-07-2018,

Acceptance 02-08-2018, Published 11-08-2018.

Corresponding Author:

Dr. Laitonjam Chinglensana,

Singjamei Thongam Leikai,

Lane 3, Imphal West-795001,

Manipur, India.

E-mail: chinglensana2rediffmail.com

DOI: $10.14260 /$ jemds $/ 2018 / 818$
Mass may be intra-abdominal or parietal in origin. Mass may develop in connection with the structures, which are normally present in this region or may originate from organs lying in other regions and abnormally invading this region. The structures normally present in this region are appendix, caecum, ileum, mesenteric lymph nodes, iliac vessels with retroperitoneal connective tissue and iliopsoas sheath. ${ }^{1}$ Surgery on intra-abdominal organs was either forbidden or disliked by the medical authorities and surgical operations upon the abdomen were not performed commonly until the beginning of the 19 th century. ${ }^{2}$

Sir Henle remarked that in any acute abdominal emergency, the greatest sacrifice was the sacrifice of time. ${ }^{3}$ Appendicular lump is the commonest swelling in this region and important differential diagnosis is between appendicular mass, abscess, carcinoma caecum and intestinal tuberculosis.

Tuberculosis (TB) is a life-threatening disease, which can virtually affect any organ system. ${ }^{4}$ According to World Health Organisation report 2013, there were an estimated 8.6 
million annual incidence of TB globally and 1.3 million people died from the disease in $2012 .{ }^{5}$ Abdominal tuberculosis can be a source of significant morbidity and mortality and is usually diagnosed late due to its non-specific clinical presentation. 6 Carcinoma of caecum is curable when diagnosed early and treated. ${ }^{7}$ Crohn's disease, Giardia Lamblia and diverticulitis of caecum, uncommon in our country are interesting causes of RIF mass.

RIF mass often poses a diagnostic as well as therapeutic challenge. This study was undertaken to assess the pattern of presentation of RIF mass and to help in the better management of these cases with proper investigation and diagnosis.

\section{MATERIALS AND METHODS}

This was a prospective observational study conducted on consecutive 100 cases in the Department of Surgery, Regional Institute of Medical Sciences, Imphal, in patients with mass in the RIF, aged between 10 - 60 years of age, admitted from September 2014 to August 2016.

Variables like age and sex, symptoms such as fever, vomiting, loss of weight, mass per abdomen, duration of symptoms and clinical signs were noted. Investigations like haemoglobin $(\mathrm{Hb}) \%$, Erythrocyte Sedimentation Rate (ESR), ultrasonography, computed tomography scan abdomen and barium study findings were done. Final diagnosis, mode of management, complication and outcome were recorded. The study was carried out after obtaining approval from the Institutional Ethics Committee (IEC), RIMS, Imphal. Data analysis was carried out using SPSS version 21.0 IBM. The confidentiality of the respondents was maintained and there was no conflict of interest.

\section{RESULTS}

Of the 100 cases of mass in the RIF, $64 \%$ of cases were related to appendicular pathology, either in the form of appendicular mass or appendicular abscess. There were 14 cases of ileocaecal tuberculosis and 12 cases of carcinoma caecum. Youngest patient was of 11 years with appendicular mass and the oldest was 60 years with carcinoma caecum. Appendicular mass manifested most commonly in age group between 20 - 29 years (21\%) followed by 30 - 39 years. Ileocaecal tuberculosis was common in the middle age group (i.e. 30 - 39 years and 40 - 49 years) covering $71.4 \%$ of cases. Carcinoma caecum was common in age group of 50 - 59 years (75\%). Male:Female ratio was 2.33:1. Appendicular mass (70.33\%) and appendicular abscess (68.75\%) were commoner in males. Ileocaecal tuberculosis occurred more in males $(71.42 \%)$ as well as carcinoma caecum (83.33\%). $91.66 \%$ of cases of appendicular mass presented within 2-30 days. Majority of the ileocaecal tuberculosis cases (10 cases out of 14 ) presented with history of 1 - 3 months. $73 \%$ cases presented within 1 month, 19\% cases presented between 1 3 months and another 5\% presented between $3-6$ months. Only 7 cases $(10.93 \%)$ of appendicular mass and abscess presented with complaints of mass in the RIF. $28.57 \%$ of ileocaecal tuberculosis patients complained of mass in the RIF and $83.33 \%$ of carcinoma caecum presented with mass. $58.33 \%$ of appendicular mass presented with fever and $54.16 \%$ presented with vomiting. Among the cases of appendicular abscess, $50 \%$ presented with fever and $37.5 \%$ presented with vomiting. Out of 14 cases of ileocaecal tuberculosis 12 cases (85.71\%) presented with fever, 5 cases had vomiting (35.71\%) and 7 cases had loss of weight (50\%).

Among 16 cases of carcinoma caecum, 7 cases gave history of occasional vomiting and 10 cases $(83.33 \%)$ gave history of loss of weight. Out of 5 cases, 4 cases of psoas abscess presented with fever. $88 \%$ cases had tenderness in RIF. $72 \%$ of patients had mass which was firm in consistency, which includes mostly cases of appendicular mass and ileocaecal tuberculosis. 68 of 100 cases presented with swelling, which were fixed. In this group it included patients of carcinoma caecum, appendicular mass and few cases of ileocaecal tuberculosis. 38\% cases had $\mathrm{Hb}<10$ gm\%. Most of the cases of ileocaecal tuberculosis and carcinoma caecum were in this group and $62 \%$ of the patients had HB more than $10 \mathrm{gm} \%$. 24 cases had ESR reading of 1 st hour between $5-20$ mm. 41 cases had reading between $21-40$ mm. In 29 (29\%) cases reading was between $41-60 \mathrm{~mm}$ and in 6 cases ESR was more than $60 \mathrm{~mm}$. All cases of ileocaecal tuberculosis had high ESR levels (> 40)

Contrast x-ray barium studies in ileocaecal tuberculosis noted pulled-up caecum with narrowed ileum. In carcinoma caecum, the main feature was irregular filling defect with shouldering sign. 91 cases had ultrasound abdomen done and all the cases were correctly diagnosed. Out of 40 cases of appendicular mass managed surgically 16 cases were taken up for surgery immediately, whereas rest of the 24 cases were managed by Ochsner-Sherren regimen and appendicectomy was done at a later date. All 16 cases of appendicular abscess and 5 cases of psoas abscess were managed by extraperitoneal drainage.

Among 9 cases of ileocaecal tuberculosis, which were managed surgically for 4 cases, limited ileocaecal resection with end-to-end anastomosis was done, whereas 3 cases underwent right hemicolectomy. In the rest 2 cases only biopsy was done, as there was associated miliary tuberculosis with unresectable mass. In 5 cases of psoas abscess, extraperitoneal drainage was done followed by which 3 cases were put on Anti-Tubercular Therapy (ATT) and other two only on antibiotics.

Out of 10 carcinoma caecum cases 8 cases underwent right hemicolectomy, 2 had only biopsy taken as they were found unresectable intraoperatively. In post-operative period, complications in the form of wound infection occurred in 24 cases and 4 cases died out of 83 cases operated.

12 cases of ileocaecal tuberculosis were on ATT and responded well. 7 cases of carcinoma caecum were on chemotherapy. 


\begin{tabular}{|c|c|c|c|}
\hline Sl. No. & Diagnosis & No. of Cases & Percentage (\%) \\
\hline 1 & Appendicular mass & 48 & 18 \\
\hline 2 & Appendicular abscess & 16 & 16 \\
\hline 3 & Ileocaecal tuberculosis & 14 & 12 \\
\hline 4 & Carcinoma of caecum & 12 & 5 \\
\hline 5 & Psoas abscess & 5 & 5 \\
\hline 6 & Others* Table 1. Diagnosis of Various Conditions \\
\hline
\end{tabular}

*Small bowel carcinoma, Lymphoma, Actinomycosis, Retroperitoneal Lymphangioma.

\begin{tabular}{|c|c|c|c|c|c|}
\hline \multirow{2}{*}{ Sl. No. } & \multirow{2}{*}{ Diagnosis } & \multicolumn{2}{|c|}{ Male } & \multicolumn{2}{|c|}{ Female } \\
\hline & & No & $\%$ & No & $\%$ \\
\hline 1 & Appendicular mass & 34 & 70.33 & 14 & 29.16 \\
\hline 2 & Appendicular abscess & 11 & 68.75 & 5 & 31.25 \\
\hline 3 & Ileocaecal tuberculosis & 10 & 71.42 & 4 & 28.57 \\
\hline 4 & Carcinoma caecum & 10 & 83.33 & 2 & 16.66 \\
\hline 5 & Psoas abscess & 3 & 60 & 2 & 40 \\
\hline 6 & Others & 2 & 40 & 3 & 60 \\
\hline Total & 100 & 70 & 70 & 30 & 30 \\
\hline
\end{tabular}

\begin{tabular}{|c|c|c|c|c|}
\hline \multirow{2}{*}{ Sl. No. } & \multirow{2}{*}{ Diagnosis } & Complaints & \multirow{2}{*}{ Percentage (\%) } \\
\cline { 2 - 5 } & Appendicular mass & 48 & 4 & $8.33 \%$ \\
\hline 1 & Appendicular abscess & 16 & 3 & $18.75 \%$ \\
\hline 2 & $\begin{array}{c}\text { Ileocaecal } \\
\text { tuberculosis }\end{array}$ & 14 & 4 & $28.57 \%$ \\
\hline 3 & Carcinoma caecum & 12 & 10 & $83.33 \%$ \\
\hline 4 & Psoas abscess & 5 & 2 & $40 \%$ \\
\hline 5 & Others & 5 & 3 & $60 \%$ \\
\hline 6 & Total Percentage & $\mathbf{1 0 0}$ & $\mathbf{2 6}$ & $\mathbf{2 6}$ \\
\hline \multicolumn{4}{|r|}{ Table 3. Presenting Symptom as Mass in RIF } \\
\hline
\end{tabular}

\begin{tabular}{|c|c|c|c|c|c|c|c|c|}
\hline \multirow{2}{*}{$\begin{array}{c}\text { Sl. } \\
\text { No. }\end{array}$} & \multirow{2}{*}{ Diagnosis } & \multirow{2}{*}{ No. of Cases } & \multicolumn{2}{|c|}{ Fever } & \multicolumn{2}{|c|}{ Vomiting } & \multicolumn{2}{|c|}{ Loss of Weight } \\
\hline & & & No & $\%$ & No & $\%$ & No & $\%$ \\
\hline 1 & Appendicular mass & 48 & 28 & 58.33 & 26 & 54.16 & - & - \\
\hline 2 & Appendicular abscess & 16 & 8 & 50 & 6 & 37.5 & - & - \\
\hline 3 & Ileocaecal tuberculosis & 14 & 12 & 85.71 & 5 & 35.71 & 7 & 50 \\
\hline 4 & Carcinoma caecum & 12 & - & - & 7 & 58.33 & 10 & 83.33 \\
\hline 5 & Psoas abscess & 5 & 4 & 80 & - & - & - & \\
\hline 6 & Others & 5 & 2 & 40 & 2 & 40 & 1 & 20 \\
\hline & Total Percentage & 100 & 54 & $54 \%$ & 46 & $46 \%$ & 18 & $18 \%$ \\
\hline
\end{tabular}

\begin{tabular}{|c|c|c|c|c|}
\hline Sl. No. & Diagnosis & No. of Patients & Type of Surgery & Percentage (\%) \\
\hline 1 & Appendicular mass & 24 & 0-S regimen with appendicectomy & 28.91 \\
\hline 2 & Appendicular abscess & 16 & $\begin{array}{c}\text { Extraperitoneal drainage with } \\
\text { interval appendicectomy }\end{array}$ & 19.27 \\
\hline 3 & $\begin{array}{c}\text { 8- carcinoma caecum, 3- ileocaeca } \\
\text { tuberculosis, 2- extra }\end{array}$ & 13 & Right hemicolectomy & 15.66 \\
\hline 4 & $\begin{array}{c}\text { 4- ileocaecal tuberculosis, } \\
\text { 2- appendicular mass, 1- extra }\end{array}$ & 7 & Limited ileocaecal resection & 8.4 \\
\hline 5 & $\begin{array}{c}\text { 2- ileocaecal tuberculosis, 2- } \\
\text { carcinoma caecum }\end{array}$ & 4 & Laparotomy with biopsy & 4.8 \\
\hline 6 & Emergency appendicectomy & 14 & Emergency appendicectomy & 16.86 \\
\hline 7 & Psoas abscess & 5 & $\begin{array}{c}\text { Extraperitoneal drainage with } \\
\text { antibiotics/ATT }\end{array}$ & 6 \\
\hline \multicolumn{7}{|r|}{ Table 5. Various Types of Surgical Treatment } \\
\hline
\end{tabular}




\section{DISCUSSION}

Mass in RIF is one of the most commonly encountered clinical conditions today. In this study $64 \%$ of cases were related to the appendicular pathology, either in the form of appendicular mass (48\%) and appendicular abscess (16\%). According to Nagar RC et al, ${ }^{8}$ appendicular mass was more common in third, fourth and second decades of life. In our study also, appendicular mass was more common in third and fourth decade followed by second and fifth decade. According to Edward L Bradley III et al, ${ }^{9}$ mean age at which appendicular abscess occurred was $40.7 \pm 2.7$ similar to our study.

In a study by Prakash A et al,10 ileocaecal tuberculosis was found between 20 - 40 years. In our study it was more common in fourth, fifth followed by sixth decade. According to Bansali SK,11 two-thirds of patients were in third and fourth decade. Most of the patients were between 45 - 65 years in a study by Amin MA et al. ${ }^{7}$ In our study, carcinoma caecum was more common in sixth decade followed by fifth decade. Appendicular mass (2.42: 1), appendicular abscess (2.2: 1) and ileocaecal tuberculosis (2.5: 1), predominantly seen in males as noted in this study is similar to those by Nagar RC et al. ${ }^{8}$

Sex incidence was equal in a study by Bhansali SK ${ }^{11}$ in ileocaecal tuberculosis, which was contradictory to our study. In this the incidence of carcinoma caecum was higher in males (83.33\%) than females (16.66\%). In a study by Pescatori et al,12 $71 \%$ of patients were males and $46 \%$ were females.

According to Charles V Mann,13 on the third day after the commencement of an attack of acute appendicitis, a tender mass can be felt in right iliac fossa beneath some rigidity of the overlying musculature, the other quadrants of abdomen being free from rigidity or tenderness.

Intestinal tuberculosis is more common in people of poor socio-economic status. In our study, $85.71 \%$ of patients with ileocaecal tuberculosis presented with fever, $50 \%$ of patients with loss of weight and only $35.71 \%$ of them had vomiting. Elhence and Sharma $\mathrm{BD}^{14}$ said gastrointestinal tuberculosis though rare in industrialised countries, continues to be a common problem in developing countries. In this study, ileocaecal tuberculosis formed $14 \%$ of cases of mass in RIF.

Tubercular enteritis is commonest in the ileocaecal region in a series conducted by Prakash A et al ${ }^{10}$ and also series conducted by Bhansali SK ${ }^{11}$ followed by involvement of ileum as the next common site. In the present study $71.4 \%$ of cases, duration of symptoms was between 1 and 3 months, $14.28 \%$ of patients presented between 2 and 30 days and $7.14 \%$ of patients presented between 3 and 6 months, which was contradictory to study by Prakash $\mathrm{A}^{15}$ in which $27 \%$ of cases had duration of symptoms of $<6$ months and $43 \%$ cases had duration ranging from 6 months to 3 years. Rest ranged more than 3 years. According to Kelly J et al,16 a high index of suspicion should be maintained for ileocaecal tuberculosis in patients with appropriate clinical feature, even if classical risk factors for tuberculosis are absent.

Carcinoma caecum accounted for $18 \%$ of the colorectal cancers according to Crerand S et al. ${ }^{17}$ In our study $83.33 \%$ cases presented with mass per abdomen, $83.33 \%$ of patients presented with loss of weight and $58.33 \%$ had vomiting.
Average duration of symptoms was from 1 - 6 months. In Goligher JC18 series growths of caecum, ascending colon and hepatic flexure, bowel symptoms were usually completely absent. In many instances, the only manifestation will be of deterioration of general health with loss of weight and anaemia. In our study, 7 patients had altered bowel habits. All the patients had pain abdomen in RIF associated with tenderness.

In the present study in $78.57 \%$ of cases, HB was less than $10 \mathrm{~g} / \mathrm{dL}$ and in $21.4 \%$ of cases HB was $>10 \mathrm{~g} / \mathrm{dL}$ in ileocaecal tuberculosis. Also 71.4\% had ESR between $40-60 \mathrm{~mm} / \mathrm{hr}$ and $28.57 \%$ of cases had ESR more than $60 \mathrm{~mm} / \mathrm{hr}$, which was similar to study by Prakash A et al 10 in which more than $50 \%$ of cases had $\mathrm{Hb} \%$ less than $10 \mathrm{~g} / \mathrm{dL}$ and ESR $>30$ $\mathrm{mm} / \mathrm{hr}$.

Investigations formed an important part of management of patients with mass in RIF. According to Ripolles T et al,19 diagnosis of appendicitis can be made in patients with right lower quadrant pain when a non-compressible appendix greater than $6 \mathrm{~mm}$ diameter is shown in ultrasound. In the present study, abdominal ultrasound was done in 91 patients and all the cases were correctly diagnosed.

In our study, out of 48 cases of appendicular mass 8 cases refused surgery. 16 cases underwent emergency appendicectomy, whereas 24 cases were initially managed by Ochsner-Sherren regimen and appendicectomy was done after 6 weeks. According to Gahukamble DB and Gahukamble LD20 "in situ" delayed appendicectomy seems beneficial for all the patients who respond well to the initial management of appendicular mass. The management of appendicular mass is surrounded with controversy. According to Garba ES and Ahmed $\mathrm{A},{ }^{21}$ conservative management is still a highly acceptable approach for appendiceal mass. This should be followed by interval appendicectomy, especially in patients with persistent RIF pain. But according to Arshad M et al, ${ }^{22}$ early appendicectomy is a safe and superior option in patients with appendicular mass compared to conventional treatment. Deu and Ghosh S23 favour operative management of appendicular mass by experienced surgeons, thus obviating the old practice of conservative treatment followed by interval appendicectomy. All those who underwent interval appendicectomy, the specimen sent for histopathological examination were reported as chronic appendicitis.

Investigations used in the diagnosis of appendicular abscess were ultrasound and computerised tomography. On computed tomography scan, appendix appears dilated and the wall is thickened. According to literature, the diagnostic accuracy with computed tomography is $92 \%$ to $97 \%$ sensitivity, $85 \%$ to $94 \%$ specificity, $90 \%$ to $98 \%$ accuracy. ${ }^{24}$

In our study, all cases of appendicular abscess underwent extraperitoneal drainage of abscess and interval appendicectomy after 6 - 8 weeks. According to Edward L Bradley et al, ${ }^{9}$ the complication rate was significantly lower, and the hospital stay was shorter during patients managed expectantly than those undergoing emergency appendicectomy. According to Hurme et al,25 if appendicular abscess is operated on in the acute phase there may be complications, but it is often not possible to make the correct diagnosis before operation.

According to Kelly J et al, a high index of suspicion should be maintained for ileocaecal tuberculosis in patients 
with appropriate clinical feature, even if classical risk factors for tuberculosis are absent. According to Schofield $\mathrm{PF}$ et al,26 in ileocaecal tuberculosis there are characteristic radiological appearances in barium enema examination like caecum is pulled up, ascending colon shortens, and ileum retains its normal calibre. FNAC confirms the diagnosis in lymphadenopathy, abscesses and focal lesions of the viscera. According to Yilmaz $\mathrm{T}$ et $\mathrm{al}^{27}$ if peritoneal thickening, ascites, abdominal lymphadenopathies and thickened intestinal walls are obtained in computed tomography abdomen, abdominal tuberculosis should be considered in differential diagnosis in developing countries.

In the present study among the 9 surgically treated cases, 3 cases underwent right hemicolectomy and 4 cases underwent limited ileocaecal resection. According to a study done by Byrom $\mathrm{HB}$ and Mann $\mathrm{CV},{ }^{28}$ resection rather than the bypass of the diseased bowel in the preferred surgical treatment. Resection by right hemicolectomy should be carried out whenever possible. ${ }^{29}$ In certain circumstances (e.g. poor general condition or concurrent procedure making a lengthy procedure unwise), a temporary ileotransverse colostomy is a sensible compromise. This is supported by Anand SS series. ${ }^{30}$ According to Elhence IP and Sharma $\mathrm{BD}^{14}$ clinical subjective improvement after surgery occurred after $2-6$ months of ATT, which may be because of surgical removal of basic tuberculosis lesion. In the present study, $64.28 \%$ of cases underwent surgery and followed by this the patients were put on ATT. These patients responded well. Standard regimen used was first 2 months of intensive phase 2 (HRZE) 3 and next 4 months of continuation phase 4 (HR) 3. After surgery, resected specimens were sent for HPE and report showed it as caseating granulomatous lesion.

In the present study, $11(91.66 \%)$ cases of carcinoma caecum underwent barium studies and 10 cases (83.33\%) underwent ultrasound of abdomen and the cases were correctly diagnosed. Richardson $\mathrm{NGB}$ et $\mathrm{al}^{31}$ said that sensitivity, specificity and accuracy of abdominal USG in colonic tumours considered to be consistent with colonic carcinoma was $96 \%$ and $97 \%$ respectively.

In the present study, 8 cases of carcinoma caecum underwent right hemicolectomy and 3 cases expired while receiving chemotherapy. According to Goligher JC18 experience with regards to growth of caecum and ascending colon, the more extensive right hemicolectomy is preferable except when patient's general condition is such as to compel restriction of the resection to the minimum that offers a reasonable chance of cure. Among the 8 operated cases of carcinoma of caecum, histopathological examination of 4 were moderately differentiated adenocarcinoma, 3 were poorly differentiated adenocarcinoma and 1 case was well differentiated adenocarcinoma. In our study, 24 patients developed wound infection following surgery and 3 patients of carcinoma caecum died while on chemotherapy and one patient of ileocaecal tuberculosis while on ATT. The patients were followed up to one year.

\section{CONCLUSION}

Appendicular lump (48\%) was the commonest condition causing mass in the RIF followed by appendicular abscess (16\%), ileocaecal tuberculosis (14\%), carcinoma caecum $(12 \%)$ and psoas abscess (5\%). Mass in RIF was common in the age group of 20 - 40 years. Overall incidence was more in males as compared to females (2.33: 1). Carcinoma caecum was more common in males $83 \%$ as compared to females $17 \% ; 26 \%$ of our patients presented with complaints of mass in the RIF. Fever, vomiting and loss of weight were the common associated symptoms. Most cases of ileocaecal tuberculosis and carcinoma caecum had low $\mathrm{Hb} \% .88 \%$ had tenderness in RIF, $72 \%$ of the cases had firm consistency mass in RIF and in $68 \%$ of cases the lump was immobile. Majority of the cases had ESR between $20-60 \mathrm{~mm} / 1^{\text {st }}$ hour. USG was done in $91 \%$ cases and all the cases were correctly diagnosed. Barium study was done in $23 \%$ cases and could diagnose the pathology correctly. $83 \%$ of the patients were managed surgically, mortality being 4 cases which included carcinoma caecum case and ileocaecal tuberculosis case. Pattern of RIF mass in this study is comparable with most of the literature reviewed. While common aetiologies should never be overlooked, rare things should also be kept in mind and special investigations should be used judiciously to further improve the diagnostic accuracy. Indiscriminate use of blanket investigations should be avoided. Surgical management remains the mainstay of management in cases of RIF mass.

\section{REFERENCES}

[1] Das S. Examination of an abdominal lump. In: Das S, edr. A manual on clinical surgery.10th edn. Calcutta: S. Das Publication 2000: p. 533-4.

[2] Laurell H. Acute abdominal pain. PhD [dissertation]. Sweden: Uppsala University 2006: p. 12.

[3] Wani M, Khan M, Wani M, et al. Analysis of acute abdomen admissions in the surgical emergency room of a developing third world country. Int J Surg 2007;11(2):1-4.

[4] Rosado E. Abdominal tuberculosis-imaging findings. Eur Radiol 2013;4(2):34-6.

[5] World Health Organization. Global tuberculosis report 2013. World Health Organization, 2013. http://apps.who.int/iris/bitstream/10665/91355/1/ 9789241564656_eng.pdf. Accessed May 16, 2018.

[6] Mukewar S, Mukewar S, Ravi R, et al. Colon tuberculosis: endoscopic features and prospective endoscopic follow-up after anti-tuberculosis treatment. Clin Transl Gastroenterol 2012;3:e24.

[7] Amin MA, Khan MA, Ayub M, et al. Delay in the diagnosis and prognosis of caecal carcinoma - a study of 20 cases. J Ayub Med Coll Abbottabad 2001;13(2):28-31.

[8] Nagar RC, Karwan DC, Sharma P. Appendix mass early appendicectomy or conservative therapy. Indian J Surg 2000;2:259-62.

[9] Bradley EL 3rd, Isaacs JP. Appendiceal abscess revisited. Arch Surg 1978;113(2):130-2.

[10] Prakash A, Sharma LK, Koshal A, et al. Ileocæcal Tuberculosis 1. ANZ J Surg 1975;45(4):371-5.

[11] Bhansali SK. The challenge of abdominal tuberculosis in 310 cases. Indian J Surg 1978;40:65-77.

[12] Pescatori M, Mattana C, Maria G, et al. Outcome of colorectal cancer. Br J Surg 1987;74(5):370-2. 
[13] Mann CV. The vermiform appendix. In: Bailey and Love short practice of surgery. 22nd edn. London: Elbs with Champan and Hall 1995: p. 828-41.

[14] Elhence IP, Sharma BD. Surgical treatment of abdominal tuberculosis. Indian J Surg 1984;46(647):337-40.

[15] Prakash A. Benign ulceroconstrictive lesions of the bowel. Indian J Surg 1976;38:213-9.

[16] Kelly J, Waren K, Coats M, et al. An unusual case of ileocaecal tuberculosis in an 80 - year old Caucasian male. Int J Clin Pract 1999;53(1):77-9.

[17] Crerand S, Feeley TM, Waldron RP, et al. Colorectal carcinoma over 30 years at one hospital: no evidence for a shift to the right. Int J Colorect Dis 1991;6(4):184-7.

[18] Goligher JC, Duthie H, Nixon H. Surgery of the anus, rectum and colon. $3^{\text {rd }}$ edn. London: Baillière Tindall 1984: p. 426-89.

[19] Ripolles T, Martinez-Perez MJ, Morote V, et al. Diseases that simulate acute appendicitis on ultrasound. $\mathrm{Br} \mathrm{J}$ Radiol 1998;71(841):94-8.

[20] Gahukamble DB, Gahukamble LD. Surgical and pathological basis for interval appendicectomy after resolution of appendicular mass in children. J Pediatr Surg 2000;35(3):424-7.

[21] Garba ES, Ahmed A. Management of appendiceal mass. Ann Afr Med 2008;7(4):200-4.
[22] Arshad M, Aziz LA, Qasim M, et al. Early appendicectomy in appendicular mass - a Liaquat University Hospital experience. J Ayub Med Coll Abottabad 2008;20(1):70-2.

[23] De U, Ghosh S. Acute appendicectomy for appendicular mass - a study of 87 patients. Ceylon Med J 2002;47(4):117-8.

[24] Stroman D, Bayouth C, Kuhn JA, et al. The role of computed tomography in the diagnosis of acute appendicitis. Am J Surg 1999;178(6):485-9.

[25] Hurme T, Nylamo E. Conservative v/s operative treatment of appendicular abscess - experience of 147 consecutive patients. Ann Chir Gynaecol 1995;84(1):33-6.

[26] Anscombe AR, Keddie NC, Schofield PF. Caecal tuberculosis. Gut 1967;8(4):337-43.

[27] Yilmaz T, Sever A, Gür S, et al. CT findings of abdominal tuberculosis in 12 patients. Comput Med Imaging Graph 2002;26(5):321-5.

[28] Byrom HB, Mann CV. Clinical features and surgical management of ileocaecal tuberculosis. Proc Royal Soc Med 1969;62(12):1230-3.

[29] Rankine JA. Tuberculosis of the ileocecal area. J Int Coll Surg 1952;18(2):202-9.

[30] Anand SS. Hypertrophic ileo-caecal tuberculosis in India with a record of fifty hemicolectomies. Ann Roy Coll Surg Engl 1956;19(4):205-22.

[31] Richardson NGB, Heriot AG, Kumar D, et al. USG in carcinoma of colon. Br J Surg 1998;55(4):50-3. 